\title{
Intestinal permeability: The basics
}

\author{
INGVAR BJARNASON MSC MD MRCPATH, ANDREW MACPHERSON PHD MRCP, IAN S MENZIES FRCPATH
}

\begin{abstract}
I BJARNASON, A MACPHERSON, IS MENZIES. Intestinal permeability: The basics. Can J Gastroenterol 1995;9(4):203-212. The authors review some of the more fundamental principles underlying the noninvasive assessment of intestinal permeability in humans, the choice of test markers and their analyses, and the practical aspects of test dose composition and how these can be changed to allow the specific assessment of regional permeability changes and other intestinal functions. The implications of increased intestinal permeability in the pathogenesis of human disease is discussed in relation to findings in patients with Crohn's disease. A common feature of increased intestinal permeability is the development of a low grade enteropathy, and while quantitatively similar changes may be found in Crohn's disease these seem to predict relapse of disease. Moreover, factors associated with relapse of Crohn's disease have in common an action to increase intestinal permeability. While increased intestinal permeability does not seem to be important in the etiology of Crohn's disease it may be a central mechanism in the clinical relapse of disease.
\end{abstract}

Key Words: Crohn's disease, Intestinal permeability, Noninvasive assessment, Test marker, Test marker analysis

\section{Perméabilité intestinale : éléments de base}

RÉSUMÉ : Les auteurs passent en revue certains des principes les plus fondamentaux de l'évaluation non effractive de la perméabilité intestinale chez l'humain, le choix des marqueurs diagnostiques et leur analyse, et les aspects pratiques de la composition des doses utilisées et de la façon dont elles peuvent être modifiées pour permettre une évaluation spécifique des changements régionaux de perméabilité et autres fonctions intestinales. Les répercussions d'une perméabilité intestinale accrue dans la pathogenèse de la maladie chez l'humain sont abordées en lien avec les résultats observés chez des patients atteints de maladie de Crohn. Une caractéristique chronique de la perméabilité intestinale voir page suivante

Departments of Clinical Biochemistry and Medicine, King's College School of Medicine and Dentistry; and Department of Chemical Pathology, St Thomas's Hospital, London, United Kingdom

Correspondence: Dr Ingvar Bjarnason, Department of Clinical Biochemistry, King's College School of Medicine $E$ Dentistry, Bessemer Road, London SE5 9PJ, United Kingdom. Telephone 0171-274-6222 ext 4108, Fax 0171-737-7434

This paper was presented at the Basic Research and Clinical Implications in IBD meeting, April 6 to 9, 1994, held in Victoria, British Columbia. This paper has also been published in Sutherland LR, et al, eds. Inflammatory Bowel Disease: Basic Research, Clinical Implications and Trends in Therapy. Boston, Dordrecht and London: Kluwer Academic Publishers, 1994
$\mathrm{T}$ WENTY YEARS AGO IT BECAME possible, with the introduction of nonmetabolized sugars as test substances, to assess intestinal permeability reliably and noninvasively in humans (1). Acceptance of the technique was initially slow, mainly because of the confusion around the use of polyethylene glycol (PEG 400) $(2,3)$, but in the past few years there has been a proliferation of published studies, from a wide range of research workers, that have used these tests to assess various aspects of gastrointestinal diseases. Tests of intestinal permeability may relate to at least five purposes: diagnostic screening for intestinal disease; confirming diagnosis - indication of therapeutic response and prognosis; evaluating the role of drug-related, dietary and environmental factors upon the intestine; determining the effect of various physiological factors on intestinal barrier function - for instance, related to diet (eg, level of food intake and osmolar content), level of nutrition and state of bloodflow; and assessing the importance of the intestinal barrier function in the etiology, pathophysiology and pathogenesis of intestinal and systemic disease.

A detailed discussion of all of the above is beyond the scope of this paper. However, a noticeable feature of many publications involving tests of intestinal permeability is a frequent failure to realize the importance of factors relating to the preparation of test solutions and conduct of test procedures. 
accrue est l'installation d'une entéropathie de bas bruit et, bien que des modifications quantitativement similaires puissent être observées dans la maladie de Crohn, elle semble pouvoir servir de facteur de prévisibilité de la rechute. De plus, les facteurs associés à la rechute de la maladie de Crohn semblent exercer une influence à la hausse sur la perméabilité intestinale. Bien que la perméabilité intestinale accrue ne semble pas importante dans l'étiologie de la maladie de Crohn, elle pourrait se révéler être un mécanisme central dans la rechute clinique de la maladie.

TABIE 1

Factors affecting the uninary exc retion of orally administered test substances: The principle of the differential urinary excretion of ingested test substances

\begin{tabular}{|c|c|c|c|c|}
\hline \multicolumn{2}{|c|}{$\begin{array}{l}\text { Factors affecting the urinary exc retion of } \\
\text { orally administered test substances }\end{array}$} & \multirow{2}{*}{$\begin{array}{c}\text { Mono- } \\
\text { saccharide } \\
=\end{array}$} & \multirow{2}{*}{$\begin{array}{c}\text { Nonhydrolyzed } \\
\text { disaccharide }\end{array}$} & \multirow{2}{*}{$\begin{array}{c}\begin{array}{r}\text { Hydrolyzed } \\
\text { disaccharide }\end{array} \\
=\end{array}$} \\
\hline Premuc osal & $\begin{array}{l}\text { Completeness of inges- } \\
\text { tion }\end{array}$ & & & \\
\hline & Gastric dilution & $=$ & $=$ & $=$ \\
\hline & Gastric emptying & $=$ & $=$ & $=$ \\
\hline & Intestina I dilution & $=$ & $=$ & $=$ \\
\hline & Intestinal tra nsit & $=$ & $=$ & $=$ \\
\hline & Bacterial degradation & $=$ & $=$ & $=$ \\
\hline & Unstirred water layer & $=$ & $=$ & $=$ \\
\hline & Digestion-hyd rolysis & 0 & 0 & + \\
\hline \multirow[t]{2}{*}{ Mucosal } & Route of permeation & $A$ & B & B \\
\hline & Intestinal bloodflow & $=$ & $=$ & $=$ \\
\hline \multirow[t]{7}{*}{ Postmucosal } & Metabolism & 0 & 0 & 0 \\
\hline & Endogenous production* & 0 & 0 & 0 \\
\hline & Tissue distribution & $\mathrm{C}$ & D & $\mathrm{D}$ \\
\hline & Renal function & $=$ & $=$ & $=$ \\
\hline & $\begin{array}{l}\text { Timing and completeness } \\
\text { of urinary collection }{ }^{\dagger}\end{array}$ & $=$ & $=$ & $=$ \\
\hline & Bacterial degradation & $=$ & $=$ & $=$ \\
\hline & Analytical performance $e^{\ddagger}$ & $=$ & $=$ & $=$ \\
\hline
\end{tabular}

*There may be some but minimal endogenous production of mannitol; ${ }^{\dagger}$ Roughly equal for the monosaccharides and disaccharides; ${ }^{7}$ Equal if thin-layer chromatography is used; =ldentical or affects all the test substances equally; 0 Does not take place; + Determined mainly by intestinal disaccharidase activities; $A$ and $B$ Different routes of permeation; $C$ and D Monosaccharides and disaccharides have a different volume of distribution following intravenous administration and hence there is a slight difference in the speed and completeness of their urinary excretions. This is for practical purposes not of major importance.

When a nonhydrolyzed disaccharide (ie, lactulose) and a monosaccharide (L-rhamnose or mannitol) are ingested together all the above factors will contribute to their excretion in urine (percentage of oral dose). However, as all the pre- and postmucosal determinants of their excretion affect the two test substances equally the urinary excretion ratio (lactulose:L-rhamnose) will only be minimally or not at all affected by these variables. The two probes differ significantly only in their routes of permeation across the intestine. The permeation pathways are affected to a different extent in small intestinal disease and are subject to specific modification to physiological stress (hyperosmolarity), damage by drugs (ie, nonsteroidal anti-inflammatory drugs) and inflammation. The urinary excretion ratio of lactulose:L-rhamnose thereby becomes a specific index of intestinal permeability which is not affected to an appreciable extent by nonmucosal factors.

The simultaneous administration of a nonhydrolyzed (lactulose) and a hydrolyzed disaccharide (lactose, sucrose or palatinose), with subsequent analysis in urine, to assess the efficacy of intestinal disaccharidase activities (lactase, sucrase and isomaltase, respectively) is an extension of the above principle. The disaccharides differ only in respect of their rate of hydrolysis in the intestine which, in turn, governs the amount of intact disaccharide available for transport across the mucosa. In normal subjects the urinary excretion (percentage of dose) ratio of hydrolyzable:nonhydrolyzable disaccharides is less than 0.3 but with increasing severity of disaccharidase deficiency (primary or secondary) this ratio approaches 1.0, at which time there is no disaccharide hydrolysis

Furthermore, many practical problems encountered when setting up the necessary clinical and laboratory procedures require attention to special details. It is important to discuss these issues to ensure that such noninvasive test procedures may be successfully exploited to assess intestinal permeability and related aspects of intestinal function.

\section{CHOICE OF MARKER: PRINCIPLE OF THE URINARY EXCRETION OF ORALLY ADMINISTERED TEST SUBSTANCES}

Testing intestinal permeability sounds simple: the subject fasts overnight, drinks a solution containing test substances the following morning, and the subsequent timed recovery of test substances in the urine indicates intestinal permeation of the administered probes.

The choice of probe employed for assessing intestinal permeability has changed somewhat through the years. Initially a single probe, such as lactulose or other nonmetabolized disaccharide (melibiose), trisaccharide (raffinose) or polysaccharide (dextrans), was used alone (1,4-6). Properties such as molecular size, water and lipid solubility, susceptibility to metabolic degradation, affinity for transport systems and toxicity, are important and require careful definition to ensure that renal excretion of the probe is determined mainly by the state of intestinal permeability (7-12).

However, even when recovery in urine following intravenous administration was complete - indicating minimal systemic loss - recovery of the probe following ingestion (usually expressed as percentage of the dose) was, as indicated in Table 1, influenced by a number of factors in addition to intestinal permeability.

To increase specificity the principle of 'differential urinary excretion' of several simultaneously ingested test substances was formulated. Table $1 \mathrm{de}$ tails the basis of this principle, which proposes that two test substances, the behaviour of which differ only in respect to the pathway of permeation across the intestinal mucosa, should be used together, for instance a monosaccharide (L-rhamnose) and a disaccharide (lactulose). In these circumstances the differential urinary excretion of disaccharide/monosaccharide after simultaneous ingestion provides a much more specific indication of the state of mucosal permeability, in this instance specifically large/small pore incidence (13), than would be indicated 
TABIE 2

Contentoflactulose/mannitol test solutionsemployed by various a uthors: Comparison of unine lactulose, mannitol and lac tulose/mannitol with test solution osmolanity and poorly absorbed solute (PAS) content of test solution

\begin{tabular}{|c|c|c|c|c|c|c|c|c|c|c|}
\hline \multirow[b]{2}{*}{ Author (reference) } & \multicolumn{3}{|c|}{ Content of test solution } & \multirow{2}{*}{$\begin{array}{l}\text { Duration } \\
\text { of urine } \\
\text { save (h) }\end{array}$} & \multirow[b]{2}{*}{$\begin{array}{c}\text { \# of sub- } \\
\text { jects }\end{array}$} & \multirow[b]{2}{*}{$\begin{array}{l}\text { Osmolanity } \\
\text { (mOsm/L) }\end{array}$} & \multicolumn{4}{|c|}{ Urinary excretion } \\
\hline & Lac (g) & Other solutes & $\begin{array}{l}\text { Vol- } \\
\text { ume } \\
\text { (mL) }\end{array}$ & & & & $\begin{array}{c}\text { Lac } \\
\text { (\% dose) }\end{array}$ & $\begin{array}{l}\text { Mannitol } \\
\text { (\% dose) }\end{array}$ & $\begin{array}{c}\text { PAS } \\
\text { content* }\end{array}$ & $\begin{array}{c}\text { Lac/ } \\
\text { mannitol }\end{array}$ \\
\hline Uka bam et al (32) & 10.0 & Nil & 100 & 6 & 33 & 320 & 0.16 & 15.6 & 32 & 0.16 \\
\hline Murphy et al (31) & 5.0 & Nil & 65 & 5 & 42 & 580 & 0.26 & 13.2 & 42 & 0.26 \\
\hline Andre et al (28) & 5.0 & Nil & 65 & 5 & 100 & 658 & 0.30 & 14.3 & 42 & 0.30 \\
\hline Wyatt et al (34) & 10.0 & Gluc ose $22 \mathrm{~g}$ & 150 & 5 & 30 & 1300 & 0.22 & 12.7 & 57 & 0.22 \\
\hline Elia et al (27) & 10.0 & Lactose $1.5 \mathrm{~g}$ & 50 & 6 & 35 & 1300 & 0.26 & 13.3 & 57 & 0.26 \\
\hline Kapembwa et al (30) & 10.0 & Nil & 50 & 6 & 19 & 1350 & 0.28 & 11.4 & 57 & 0.28 \\
\hline van der Hulst et al (33) & 10.0 & Xylose $5.0 \mathrm{~g}$ & 65 & 6 & 12 & 1474 & 0.4 & 17.6 & 32 & 0.40 \\
\hline J uby et al (29) & 5.0 & Glucose $22.3 \mathrm{~g}$ & 100 & 5 & 12 & 1500 & 0.44 & 28.5 & 26 & 0.44 \\
\hline Blomquist et (26) & 5.0 & Glycerol $2.0 \mathrm{~g}$ & 50 & 6 & 28 & 1700 & 0.60 & 15.7 & 35 & 0.60 \\
\hline
\end{tabular}

${ }^{*}$ mOsm per test dose; Lac Lactulose

by the urinary recovery of either probe alone.

Usually lactulose, melibiose or raffinose has been employed in combination with either L-rhamnose or mannitol. Cellobiose has also been proposed, but the suitability of this probe has been questioned because of the presence of some intestinal cellobiase activity (14). ${ }^{51}$ CrEDTA, which apart from resistance to bacterial degradation has properties almost identical to those of lactulose, can be substituted for lactulose but this is not ideal because small intestinal bacterial overgrowth (causing degradation of L-rhamnose and mannitol) or a particularly rapid intestinal transit (reducing the effective mucosal contact time of L-rhamnose) may give rise to an increased ${ }^{51}$ CrEDTA: monosaccharide urinary excretion ratio in the absence of a genuine alteration of permeability.

PEG 400 should be avoided when testing for intestinal permeability for the following reasons. First, PEG 400 polymers, despite physicochemical similarities (eg, size and solubility) to nonmetabolized disaccharides and monosaccharides, permeate the small intestine 10 to 50 times more readily than saccharides of similar mass. The precise reason for such atypical permeation is uncertain, but discussion has centred on the question of molecular shape or lipid solubility (10,15-19). In any case a readily permeating test substance is inappropriate for assessing barrier function. Second, recovery of
PEG 400 in human urine following intravenous administration is incomplete and varies between $26 \%$ and $72 \%$ of the administered dose excreted within 5 h (13). As PEG 400 is not known to be metabolized it is surprising that recovery in the urine is so low and ceases within $10 \mathrm{~h}$ of intravenous administration. Such a brief and incomplete recovery suggests that these polymers must be retained in the tissues. Third, PEG 400 is not appropriate for assessing the profile of intestinal permeability because this range of polymers appears to use the same diffusion pathway. Diagnostically meaningful alterations in permeation ratio have not yet been described. Fourth, altered permeation of PEG 400 recorded in various diseases does not correlate in a logical fashion with any aspect of intestinal physiology or pathology. Finally, the PEG 400 test lacks sensitivity, and only a marginal improvement is achieved by mathematical manipulation (filter function or $\left.\mathrm{N}_{\frac{1}{2}}\right)(20-23)$.

\section{TEST DOSE COMPOSITION}

It is the purpose of the investigation that determines test dose composition. It is informative to review the main developments of test dose composition in a historical context: first, with respect to the use of 'osmotic fillers', the effects of which have been responsible for considerable confusion, and then test marker composition.

Effects of poorly absorbed solute on intestinal absorption: Inclusion of slowly absorbed solutes, such as lactulose, mannitol and L-rhamnose, in the preparation of test solutions induces retention of fluid within the intestinal lumen and stimulates peristaltic activity, which by reducing concentration gradients and duration of contact with the absorptive surfaces reduces absorptive uptake (otherwise permeation) of all test substances (24). In the presence of small intestinal malabsorption it should be remembered that solutes normally well absorbed often become poorly absorbed and behave in a similar way.

Effects of hyperosmolar solutions 'hyperosmolar stress': Early investigators (1) indicated the importance of controlling the osmolarity of ingested test solutions in relation to urinary excretion of lactulose and other oligosaccharides. 'Hyperosmolar stress', represented by ingestion of a solution of 100 $\mathrm{mL}$ volume above $1500 \mathrm{mOsm} / \mathrm{L}$, was found to increase intestinal permeation of disaccharide but not monosaccharide in healthy human subjects (1,4-6,25). The observation that hyperosmolar stress at the $1500 \mathrm{mOsm} / \mathrm{L}$ threshold produced no significant effect on normal intestine of controls, while patients with villus atrophy demonstrated a significant rise in permeability, led to the use of hyperosmotic test solutions in the belief that they would increase diagnostic discrimination. Several osmotic fillers were used: a mixture of sucrose and lactose, glycerol, glucose, etc. Unfortunately osmotic fillers tend to differ in their behaviour 
in the intestine and consequent osmotic potency. Furthermore, the osmolarity of test solutions employed by different workers (26-34) varied widely and, as a consequence, results obtained failed to correspond. This problem is well illustrated in Table 2 . The choice of osmotic filler needs very careful attention to avoid additional unwanted variables. Variations in hydrolysis of lactose and sucrose are particularly liable to complicate the action of these sugars which are best avoided as osmotic fillers. The absorption of D-glucose, which is sodium coupled, may also represent a variable that is best avoided. Although the effect of osmotic fillers, which may be poorly absorbed, would not alter disaccharide: monosaccharide permeation ratios, the percentage of monosaccharide recovery in urine (which provides a valuable assessment of absorptive capacity) is certainly reduced. Probes for the latter purpose (3-o-methyl-D-glucose, D-xylose and L-rhamnose) are critically dependent on test dose composition, as well as the completeness and accurate timing of urine collections. Perhaps the best advice would be to avoid osmotic fillers because their use has not, in general, achieved a better diagnostic discrimination.

Test markers: ${ }^{51}$ CrEDTA can be used alone, but $24 \mathrm{~h}$ urinary excretion includes a substantial amount of the probe passing across the colon and small intestine. ${ }^{51}$ CrEDTA alone does not allow the specific assessment of intestinal permeability. Nevertheless, increased urinary excretion of this marker in diseases has almost invariably been shown to be associated with increased disaccharide:monosaccharide urinary excretion ratios $(29,35-41)$.

Lactulose is the most widely used disaccharide in tests of intestinal permeability. It resists action of small intestinal disaccharidases and is not widely distributed in foods although commonly used as a laxative and in the treatment of hepatic encephalopathy. Prohibitively expensive when purchased as powder, lactulose is available as a reasonably priced syrup. (The additional osmolarity of the syrup should be noted when preparing test solutions.)
Melibiose also resists intestinal disaccharidase and has been successfully employed as an alternative to lactulose, particularly in liver failure patients, many of whom take lactulose. Raffinose, a trisaccharide, can also be used. There is little to choose between the monosaccharides L-rhamnose and mannitol. The latter has theoretical advantages because urinary excretion following intravenous administration simulates urinary excretion following ${ }^{51}$ CrEDTA and lactulose more closely than that of L-rhamnose $(13,42-45)$, but mannitol is present in certain foods and cannot be quantitatively estimated by thin-layer chromatography because the colour reaction lacks sufficient sensitivity. Lactulose and monosaccharide probes should be administered in low doses because these substances have limited intestinal permeation and thus cause osmotic fluid retention within the bowel as already described (24).

For routine assessment of small intestinal permeability in humans a 100 $\mathrm{mL}$ test solution should include lactulose or equivalent nonhydrolyzable oligosaccharide (not more than $5 \mathrm{~g}$ ) and L-rhamnose $(1.0 \mathrm{~g})$ or mannitol (no more than $2 \mathrm{~g}$ ). A $5 \mathrm{~h}$ urine collection should be made into a container with sufficient preservative (eg, merthiolate $100 \mathrm{mg}$ ) to prevent bacterial degradation of sugars. For the combined assessment of intestinal permeability and absorptive capacity 3-o-methyl-D-glucose $(0.2 \mathrm{~g})$, which assesses an active carrier mediated process in the enterocytes, and D-xylose (0.5 g), which assesses a passive carrier mediated transport system, should be added to the above test solution.

A complete and accurate urine recovery is essential because an incomplete collection will underestimate absorptive capacity. The adequacy of both renal function and urine collection can be confirmed by estimating serum and urine creatinine concentrations and calculating a creatinine clearance index.

\section{ANALYSES OF TEST MARKERS}

Reliable analysis of sugar markers in urine requires great care and experience. Column chromatography (gas- liquid chromatography and high performance liquid chromatography) has proven to be difficult to control, but quantitative thin-layer chromatography has proved a reliable method (still requiring adequate experience and manual skill), enabling samples to be 'batched'. Introduction of a technique of 'multiple application' enables precise analysis of the very low urine disaccharide concentrations obtained with these tests $(46,47)$. Enzyme analyses for lactulose has had some proponents. Stability and specificity of the enzyme preparation are important, and a 'control' analysis to make due allowances for preexisting monosaccharides present in urine is essential. For estimation of lactulose it should be remembered that it is necessary to estimate fructose rather than the galactose generated by incubation with beta-galactosidase, otherwise any lactose present will be mistakenly included. Radiolabelling the probes is yet another possibility. However, because these sugars are inert, the radiolabel needs to be incorporated into its basic structure. ${ }^{14} \mathrm{C}$-labelled L-rhamnose and mannitol are available. There is a substantial problem if ${ }^{51}$ CrEDTA is used concomitantly with ${ }^{14} \mathrm{C}$ because both isotopes have a similar beta radiation spectrum that is difficult to separate. Whatever technique is used the analytical performance (accuracy and sensitivity) should be clearly stated.

\section{EXPANDING THE PRINCIPLE OF URINARY EXCRETION OF ORALLY ADMINISTERED TEST PROBES}

Assessment of colonic permeability: By noting the principle of urinary excretion of orally administered test probes it is possible to combine the use of commonly used markers of intestinal permeability with specially selected ones that allow various other intestinal functions to be assessed noninvasively. One such modification is to administer ${ }^{51}$ CrEDTA with lactulose and L-rhamnose followed by a 5 and $24 \mathrm{~h}$ urine collection for marker analyses $(48,49)$. The principle is that lactulose and L-rhamnose are both rapidly degraded by colonic bacteria while 51 CrEDTA is 
not. Additionally, in most aspects ${ }^{51}$ CrEDTA has physicochemical properties identical to those of lactulose (apart from the bacterial degradability of the latter). Certainly in ileostomy patients equal amounts appear in urine following simultaneous oral administration. However, when ${ }^{51}$ CrEDTA, lactulose and L-rhamnose are ingested together and urine collected for the next $5 \mathrm{~h}$, there is always a bit more ${ }^{51}$ CrEDTA than lactulose (13). This is almost certainly due to presence and availability of ${ }^{51}$ CrEDTA to permeate across part of the intestine where the concentration of lactulose has been eliminated by bacterial degradation, namely the colon. When the total $24 \mathrm{~h}$ urinary excretion of lactulose is subtracted from that of ${ }^{51}$ CrEDTA the difference represents what has permeated through the colon (or more precisely that part of the intestine containing an active bacterial flora, which may also include the lower ileum). The technique has only been used in a limited number of diseases, but its simplicity suggests that it may have much wider application.

Localizing intestinal permeability changes: The above technique allows the simultaneous assessment of small and large bowel permeability. A more labour-intensive and accurate technique has been used that may be useful for assessing the precise intestinal location of various absorptive processes (such as iron and calcium absorption) and perhaps for assessing the efficacy of drug delivery systems.

The principle of the technique is that a range of test substances, whose absorptive site is well defined to a particular region of the intestine, are given orally with subsequent serum analyses (50). The absorption profile of the test substance, in this case ${ }^{51}$ CrEDTA, is then compared with that of the other markers, which allows the site of increased intestinal permeability to be assessed. The test substances are: 3-o-methyl-D-glucose, absorbed predominantly from the jejunum; ${ }^{57} \mathrm{Co}$ vitamin $\mathrm{B}_{12}$, absorbed from the terminal ileum; and sulfasalazine, which passes unchanged into the cecum where it is cleaved into 5-aminosalicylic acid and sulphapyridine by azo reductase con- taining bacteria. Sulphapyridine is rapidly absorbed, and its appearance in serum indicates when the test solution enters the cecum.

The absorption profile from patients with untreated celiac disease shows increased serum levels of ${ }^{51}$ CrEDTA corresponding to the 3-o-methyl-D-glucose absorption curve. Similarly the peak serum levels of ${ }^{51}$ CrEDTA in patients with ileal Crohn's disease correspond to the appearance of the ileal and colonic marker, while patients with severe total colitis have peak levels following the appearance of these markers. This is in keeping with the idea that the main site of increased intestinal permeability in patients with celiac and inflammatory bowel disease is the diseased intestinal mucosa.

Assessment of intestinal disaccharidase activities: By noting the principle of the differential urinary excretion of orally administered test substances it is possible to design noninvasive tests that specifically quantify intestinal disaccharidase activities (51,52, unpublished data). Table 1 shows the variables that determine the amount of intact disaccharide excreted in urine following oral administration.

Simultaneous ingestion of lactulose and melibiose, which both resist mucosal hydrolysis, gives a urine excretion (percentage dose) ratio of melibioselactulose of 1.0 because these oligosaccharides do not differ in their properties and permeation pathways. However, if a hydrolyzable disaccharide is substituted for melibiose all the variables in Table 1 will affect the two test substances equally except the enzymatic degradation of the hydrolyzable disaccharide. The amount available for permeation is, in this case, determined by the rate of intestinal hydrolysis (disaccharidase activities) relevant for that sugar. Sucrose, lactose and palatinose, being substrates for sucrase, lactase and isomaltase, respectively, can be given with lactulose. Normal urinary excretion ratios of sucrose, lactose or palatinose to that of lactulose in 5 or $10 \mathrm{~h}$ urines following their oral administration are 0.3 or below in subjects with active intestinal disaccharidase hydrolysis. Ratios of 0.3 to 1.0 indicate increasing impairment of intestinal hydrolysis. Clinically relevant impairments of lactase activity are usually associated with lactose:lactulose urinary excretion ratios of 0.45 or greater in $10 \mathrm{~h}$ urine. The technique has been used to demonstrate transient lactase deficiency following rotavirus enteritis in children (53), combined sucrase and palatinase deficiency in asucrasia $(51,52,53)$ and effectiveness of alphaglucosidase inhibitors on sucrose hydrolysis, and to quantify total small intestinal hydrolytic activity in patients with celiac disease (unpublished data). The technique seems to have potential as a routine noninvasive screening test for intestinal disaccharidase deficiency and may discriminate between isolated, usually genetically determined, disaccharidase deficiency and acquired pan-disaccharidase deficiency associated with small intestinal disease. Because excretion of dietary lactose and sucrose is a natural phenomenon in normal subjects, it is necessary to exclude all dietary sources of lactose and sucrose for at least $18 \mathrm{~h}$ before and during the period of urine collection.

\section{INTESTINAL PERMEABILITY IN CROHN'S DISEASE}

The intriguing question, however, is whether altered intestinal permeability plays an etiological or pathogenic role in Crohn's disease (54-56). The problem is familiar to clinical investigators interested in inflammatory bowel disease: deciding whether the abnormalities are the cause or result of pathology (40). In this case the problem has not so much to do with the interpretation of data as the importance of looking at the problem from a different perspective and in context of results obtained in other diseases, a feature lacking from much recent, uncritical and high profile work.

\section{PATHOGENIC IMPORTANCE OF INCREASED INTESTINAL PERMEABILITY}

Tests of intestinal permeability were specifically designed to assess the intestinal barrier function. It is the integrity of this barrier that is thought to be im- 
portant for limiting macromolecular permeation. Increased macromolecular permeation may play a role in systemic and local disease $(57,58)$. In the latter situation it is important to assess and integrate all available data to assess whether a story is emerging.

It is suggested that increased intestinal permeability allows mucosal exposure of luminal aggressive factors, and an inflammatory reaction consequentially sets in because of the generation of or exposure to neutrophil chemotactic factors (59-61). The present authors have suggested that this is a central pathophysiological mechanism in a number of small intestinal diseases. Indeed there may be three ways of initiating intestinal damage, all of which lead to increased intestinal permeability, the prerequisite for an intestinal inflammatory reaction. The three mechanisms are broadly classified as: primary permeability breakers; factors or disease associated with enhanced luminal aggressiveness; or diminished mucosal defence. It is of interest to compare the changes in intestinal permeability with quantitate intestinal inflammation in these diseases.

Intestinal permeability breakers NSAID-induced small intestinal damage: Following ingestion of nonsteroidal anti-inflammatory drugs (NSAIDs) there is a uniform and consistent increase in intestinal permeability. This occurs within $12 \mathrm{~h}$ of ingestion of the drugs and occurs predominantly during drug absorption when the enterocytes are exposed to the highest concentration of the drugs (40,62-66).

Quantitatively the increased intestinal permeability in response to NSAID ingestion does not differ from that seen in other small intestinal disorders such as Crohn's or celiac disease. Moreover there is no significant difference in the permeability changes following short or long term ingestion of NSAIDs.

Three lines of evidence show that NSAIDs cause small intestinal inflammation, namely ${ }^{111}$ In-labelled leukocytes, enteroscopy and postmortem studies $(61,67-70)$. Collectively the data show that $65 \%$ of patients on long term NSAIDs develop small intestinal inflammation. The fecal excretion of
${ }^{111}$ In shows that most patients have a low grade enteropathy with a fecal excretion of 1 to $6 \%$ (normal less than $1 \%)$. Once the inflammation is present patients bleed from the inflammatory site and lose protein, both of which are clinically relevant in patients with arthritis because they are prone to iron deficiency and hypoalbuminemia.

In short, NSAIDs have a specific detrimental biochemical action on enterocytes which is not evident to the same extent in other tissue because of lower drug concentrations. The ultrastructural-biochemical alterations lead to increased intestinal permeability, resulting in a low grade enteropathy or substantial inflammation when normal intestinal defence mechanisms are intact or disrupted, respectively.

Alcohol-induced intestinal damage: Only a few studies have assessed intestinal permeability in alcoholic patients. The permeability changes were comparable with those found in Crohn's and celiac disease (38). Increased intestinal permeability, unlike that observed with NSAIDs, was not seen following single doses of alcohol $(1,71)$. Very limited data were available on possible intestinal inflammation in these patients. In five of eight heavy drinkers the authors found a low grade enteropathy, with fecal excretions ranging from 1.2 to $4.3 \%$ (unpublished data).

Enteropathy of chronic renal failure: There are formidable difficulties associated with the noninvasive measurement of intestinal permeability in patients with chronic renal failure. The authors found increased intestinal permeability (lactulose/L-rhamnose) in a small group of patients (unpublished data). These patients had an enteropathy with a fecal excretion of ${ }^{111}$ In ranging from 2 to $9 \%$. It is suggested that the uremia or other circulating toxins somehow interfere directly with enterocyte function or alter mucosal defence processes (specific or nonspecific), resulting in increased intestinal permeability with its consequences.

Miscellaneous: Antineoplastic agents increase intestinal permeability (72. 75), and increased intestinal permeability is also evident in patients with diabetes mellitus (76) and in patients undergoing major surgery or experiencing intestinal ischemia (77-79), or following major burns or abdominal radiation (80-82). Apart from abdominal radiation where there is evidence of an inflammatory reaction (personal communication) of severity comparable with that of NSAID enteropathy, it remains to a large extent to be explored whether the increased intestinal permeability in these situations leads to an inflammatory response.

Luminal aggressive factors: Various exogenous microbial infections increase intestinal permeability to an extent similar to that seen with the permeability breakers and in Crohn's and celiac disease (53). The increased intestinal permeability may be an essential component in the pathogenesis of the intestinal infection, allowing mucosal exposure of the microbe, or it may be the consequence of neutrophilinduced tissue damage as detailed above or due to cytokine release. Whatever the mechanism there is a moderately severe inflammatory response evident in these patients with 111In leukocyte excretion levels between 1 and 9\% (83).

Patients with cystic fibrosis have striking increases in intestinal permeability (84-87), possibly because the viscous mucous provides a nidus for small intestinal microbial proliferation. Again the possibility that these patients develop an enteropathy remains to be examined.

Altered mucosal defence: Patients with hypogammaglobulinemia have been studied in some detail. Increased intestinal permeability is a universal feature and the fecal excretion of ${ }^{111}$ In leukocytes in these patients ranges from 1.1 to $14.5 \%$, mean $6.9 \%$ (88).

Patients with the acquired immunodeficiency syndrome (AIDS) have increased intestinal permeability regardless of subgrouping $(89,90)$. Studies with ${ }^{111}$ In leukocytes showed that all those with increased intestinal permeability had a low grade enteropathy similar in severity to that found in NSAID enteropathy (unpublished data).

The above data conform to buttress 
a central importance of the intestinal barrier function. They show that by whatever means one disrupts the integrity of this barrier there is a uniform inflammatory response, presumably and predominantly to luminal factors. It is now appropriate to reexamine the situation in Crohn's disease.

\section{INTESTINAL PERMEABILITY AND INFLAMMATION IN CROHN'S DISEASE}

Tests of intestinal permeability provide noninvasive functional assessment of the small intestine in patients with Crohn's disease $(36,91)$ and ulcerative colitis. Most patients with small intestinal involvement of Crohn's disease who have not undergone intestinal resection have increased intestinal permeability, as assessed by the differential urine excretion of disaccharides/monosaccharides and ${ }^{51}$ CrEDTA, and $50 \%$ of patients with colonic Crohn's disease are abnormal (28,31,36,91-105). The permeability changes relate to the extent of disease as well as activity. Of particular importance is the fact that the permeability changes are of equal magnitude to those of the above-mentioned diseases.

Similarly, studies with ${ }^{111}$ In leukocytes show all patients with active Crohn's disease have increased fecal excretion of neutrophils. However, unlike that seen in NSAID-induced enteropathy and other diseases, the fecal excretion of labelled neutrophils is almost an order of magnitude higher, averaging $18 \%$, range 10 to $60 \%$ depending on disease activity. It is the inREFERENCES

1. Menzies IS. Absorption of intact oligosaccharide in health and disease. Biochem Soc Trans 1974;2:1040-6.

2. Chadwick VS, Phillips SF, Hofman

AF. Measurements of intestinal permeability using low molecular weight polyethylene glycols (PEG 400). I. Chemical analysis and biological properties of PEG 400. Gastroenterology 1977;73:241-6.

3. Chadwick VS, Phillips SF, Hofman AF. Measurements of intestinal permeability using low molecular weight polyethylene glycols (PEG 400). II. Application to study of tensity of the neutrophil response that needs explanation.

Most researchers feel confident that preliminary reports of increased intestinal permeation of PEG 400 in firstdegree relatives of patients with Crohn's disease are incorrect (106108). Intestinal permeability is normal in relatives tested with the differential urinary excretion of sugars or ${ }^{51}$ CrEDTA $(106,109)$ with the occasional subject $(12,106,109-111)$ being abnormal, presumably because of alcohol, NSAIDs, etc.

Recent evidence indicates that normal intestinal permeability in patients with Crohn's disease predicts well-being $(34,99,102)$; as permeability improves following treatment $(98,99)$ it has been suggested that the main importance of increased intestinal permeability in patients with inflammatory bowel disease is that it is the central mechanism of relapse of the disease. This would then expose patients to the same luminal aggressive factors as in the other enteropathies, but the severity of the neutrophil response, which may relate to the underlying immune derangement of the disease, is what distinguishes Crohn's disease clinically and pathophysiologically from the otherwise low grade enteropathies. The relapse of Crohn's disease is then not an activation of the disease process itself but a nonspecific, unchecked acute inflammatory response to normal intestinal flora caused by a breach in intestinal permeability and amplified by the disease itself. This hypothesis certainly provides a comprehensive,

normal and abnormal permeability states in man and animals.

Gastroenterology 1977;73:247-51.

4. Laker MF, Menzies IS. Increase in human intestinal permeability following ingestion of hypertonic solutions. J Physiol (Lond) 1977;273:881-94.

5. Laker MF. The effect of hypertonic solutions on intestinal permeability. University of London, 1978. (Thesis)

6. Wheeler PG, Menzies IS, Creamer B. Effect of hyperosmolar stimuli and coeliac disease on the permeability of the human gastrointestinal tract. Clin Sci Mol Med 1978;54:495-501.

7. Bjarnason I, Peters TJ, Levi AJ. logical and testable framework for further investigations.

\section{CONCLUSIONS}

Tests of intestinal permeability have come a long way in the 20 years since they were introduced. Their use is simple, and they are accurate, sensitive and provide information not obtainable noninvasively by the use of single markers. There are nevertheless many practical aspects of their use that need special attention, lest unpublishable data are obtained and time wasted. We have outlined many of the common pitfalls involved when deciding on test dose composition and the method of urinary analyses of the markers. Most important, prospective workers are well advised to confer with established workers before embarking on their projects. By exploiting the details of the underlying principles of the differential urinary excretion of orally administered test markers, new tests have been introduced that allow the specific assessment of regional permeability changes and the noninvasive assessment of disaccharidase activities of the whole of the small intestine. It seems clear that further development of other noninvasive techniques for assessing other intestinal functions is limited only by the ingenuity of the investigator. An integrated approach to the study of intestinal permeability and inflammation in various diseases and in classic inflammatory bowel disease provides insight into the basic mechanisms of a common final pathway for an intestinal inflammatory response.

Intestinal permeability: Clinical correlates. Dig Dis 1986;4:83-92.

8. Hamilton I. Small intestinal permeability. In: Pounder RE, ed.

Recent Advances in Gastroenterology, vol 6. Edinburgh: Churchill

Livingstone, 1986:73-91.

9. Cooper BT. The small intestinal permeability barrier. In: Losowski $\mathrm{MH}$, Heatley RV, eds. Gut Defences in Clinical Practice. Edinburgh: Churchill Livingstone, 1986:117-32.

10. Menzies IS. Transmucosal passage of inert molecules in health and disease. In: Skadhauge E, Heintze K, eds. Intestinal Absorption and Secretion. Falk Symposium 36. Lancaster: MTP Press, 1984:527-43. 
11. Hollander D. The intestinal permeability barrier. A hypothesis as to its regulation and involvement in Crohn's disease. Scand J Gastroenterol 1992;27:721-6.

12. Hollander D. Permeability in Crohn's disease - Altered barrier function in healthy relatives? Gastroenterology 1993;104:1848-51.

13. Maxton DG, Bjarnason I, Reynolds AP, Catt SD, Peters TJ, Menzies IS. Lactulose, ${ }^{51}$ CrEDTA, L-rhamnose and polyethylene glycol 400 as probe markers for "in vivo" assessment of human intestinal permeability. Clin Sci 1986;71:71-80.

14. Dahlqvist A. Specificity of human intestinal disaccharidases and implications for hereditary disaccharide intolerance. J Clin Invest 1962;41:463-70.

15. Hollander D, Rickets D, Boyd CAR. Importance of 'probe' molecular geometry in determining intestinal permeability. Can J Gastroenterol 1988;2(Suppl A):35A-8A.

16. Ma TY, Hollander D, Krugliak P, Katz K. PEG 400, a hydrophillic molecular probe for measuring intestinal permeability. Gastroenterology 1990;98:39-46.

17. Krugliak P, Hollander D, Ma TY, et al. Mechanism of polyethylene glycol 400 permeability of perfused rat intestine. Gastroenterology 1989;97:1164-70.

18. Krugliak P, Hollander D, Le K, Ma T, Dadufalza VD, Katz KD. Regulation of polyethylene glycol 400 intestinal permeability by endogenous and exogenous prostanoids. Influence of non-steroidal anti-inflammatory drugs. Gut 1990;31:417-21.

19. Iqbal TH, Lewis KO, Cooper BT. Diffusion of polyethylene glycol-400 across lipid barriers in vitro. Clin Sci 1993;185:111-5.

20. Magnusson KE, Sundqvist T. Mathematical modelling for determining intestinal permeability using polyethylene glycol. Gut 1983;25:428-9.

21. Magnusson KE, Sundqvist T. Modelling of intestinal permeability in man to polyethylene glycols (PEG 400 and PEG 1000). Acta Physiol Scand 1985;125:289-96.

22. Sundqvist T, Tageson C, Magnusson KE. Simulation of a multicompartment model for the intestinal permeability to low-molecular-weight probes (polyethylene glycol 400). Math Biosci 1981;56:287-309.

23. Irving CS, Lifschitz CH, Marks LM, Nichols BC, Klein PD. Polyethylene glycol polymers of low molecular weight as probes of intestinal permeability. I. Innovations in analyses and quantitation. J Lab Clin Med 1986;107:290-8.

24. Menzies IS, Jenkins AP, Heduan E, Catt SD, Segal MB, Creamer B. The effect of poorly absorbed solute on intestinal absorption. Scand J Gastroenterol 1990;25:1257-64.

25. Menzies IS, Pounder R, Heyer S, et al. Abnormal intestinal permeability to sugars in villus atrophy. Lancet 1979;ii:1107-9.

26. Blomquist L, Bark T, Hedenborg G, Svenberg T, Norman A. A comparison between the lactulose/mannitol and ${ }^{51} \mathrm{CrEDTA} /{ }^{14} \mathrm{C}$-mannitol methods for intestinal permeability. Scand J Gastroenterol 1993;28:274-80.

27. Elia M, Beherens R, Northrop C, Wraight P, Neale G. Evaluation of mannitol, lactulose and ${ }^{51} \mathrm{Cr}$ labelled ethylenediaminetetraacetate as markers of intestinal permeability in man. Clin Sci 1987;73:197-204.

28. Andre F, Andre C, Emery Y. Assessment of the lactulose-mannitol test in Crohn's disease. Gut 1988;29:511-5.

29. Juby LD, Rothwell J, Axon ATR. Lactulose/mannitol test. An ideal screening test for coeliac disease. Gastroenterology 1989;96:79-85.

30. Kapembwa MS, Fleming SC, Sewankambo N, et al. Altered small-intestinal permeability associated with diarrhoea in humanimmunodeficiency-virus-infected Caucasian and African subjects. Clin Sci 1991;81:327-34.

31. Murphy MS, Eastham EJ, Nelson R, Pearson ADJ, Laker MF. Intestinal permeability in Crohn's disease. Arch Dis Child 1989;64:321-5.

32. Ukabam SO, Homeda MA, Cooper BJ. Small intestinal permeability in Sudanese subjects: Evidence of tropical enteropathy. Trans R Soc Trop Med Hyg 1986;40:204-7.

33. van der Hulst PRWJ, Kreel BK, Meyenfelt MF, et al. Glutamine and the preservation of gut integrity. Lancet 1993;341:1363-5.

34. Wyatt J, Vogelsang H, Hubl W, Waldhoer T, Lochs H. Intestinal permeability and the predictor of relapse in Crohn's disease. Lancet 1993;341:1437-9.

35. Bjarnason I, Peters TJ, Veall N. A persistent defect of intestinal permeability in coeliac disease as demonstrated by a ${ }^{51} \mathrm{Cr}$-labelled EDTA absorption test. Lancet 1983;i:323-5.

36. Bjarnason I, O'Morain C, Levi AJ, Peters TJ. The absorption of ${ }^{51} \mathrm{Cr}$ EDTA in inflammatory bowel disease. Gastroenterology 1983;85:318-22.

37. Bjarnason I, Williams $\mathrm{P}$, So A, et al.
Intestinal permeability and inflammation in rheumatoid arthritis: effects of non-steroidal antiinflammatory drugs. Lancet 1984;ii:1171-4.

38. Bjarnason I, Ward K, Peters TJ. The leaky gut of alcoholism: possible route of entry for toxic compounds. Lancet 1984;i:179-82.

39. Bjarnason I, Goolamali SK, Levi AJ, Peters TJ. Intestinal permeability in patients with atopic eczema. $\mathrm{Br} J$ Dermatol 1985;112:291-7.

40. Bjarnason I, Peters TJ. Helping the mucosa make sense of macromolecules. Gut 1987;28:1057-61.

41. Hamilton I, Fairris GM, Rothwell J, Cunliffe WJ, Dixon MF, Axon ATR. Small intestinal permeability in dermatological disease. Q J Med 1985;56:559-67.

42. Laker MF, Bull HJ, Menzies IS. Evaluation of mannitol for use as a probe marker of gastrointestinal permeability in man. Eur J Clin Invest 1982;12:485-91.

43. Cobden I, Hamilton I, Rothwell J, Axon ATR. Cellobiose/mannitol test: Physiological properties of probe molecules and influence of extraneous factors. Clin Chim Acta 1985;148:53-62.

44. Dominguez R, Corcoran AC, Page IH. Mannitol: kinetics of distribution, excretion and utilization in human beings. J Lab Clin Med 1947;32:192-202.

45. Newman EV, Bordlay J, Winternitz J. The interrelationship of glomerular filtration rate (mannitol clearance), extracellular fluid volume, surface area of the body, and plasma concentration of mannitol. Bull Johns Hopkins Hospital 1944;75:253-68.

46. Menzies IS. Quantitative estimation of sugars in blood and urine by paper chromatography using direct densitometry. J Chromatogr 1983;81:109-27.

47. Menzies IS, Mount JN, Wheeler MJ. Quantitative estimation of clinically important monosaccharides in plasma by rapid thin layer chromatography. Ann Clin Biochem 1978;15:65-76.

48. Jenkins AP, Nukajam WS, Menzies IS, Creamer B. Simultaneous administration of lactulose and ${ }^{51} \mathrm{Cr}$-ethylenediaminetetraacetic acid. A test to distinguish colonic from small-intestinal permeability change. Scand J Gastroenterol 1992;27:769-73.

49. Jenkins AP, Trew DR, Crump BJ, Menzies IS, Creamer B. Do nonsteroidal anti-inflammatory drugs increase colonic permeability? Gut 1991;32:66-9.

50. Teahon K, Smith T, Smethurst P, Bjarnason I. A technique for localizing 
alterations of intestinal permeability in man. Gastroenterology

1991;100:A251.

51. Maxton DG, Catt SD, Menzies IS. Intestinal disaccharidases assessed in congenital asucrasia by differential urinary disaccharide excretion. Dig Dis Sci 1989;34:129-31.

52. Maxton DG, Catt SD, Menzies IS. Combined assessment of intestinal disaccharidases in congenital asucrasia by differential urinary disaccharide excretion. J Clin Pathol 1990;43:406-9.

53. Ford RPK, Menzies IS, Phillips AD, Walker-Smith JA, Turner MW. Intestinal sugar permeability: Relationship to diarrhoeal disease and small bowel morphology. J Pediatr Gastroenterol Nutr 1985;4:568-74.

54. Hollander D. Crohn's disease A permeability disorder of the tight junctions? Gut 1988;26:1621-4.

55. Hollander D, Vadheim C, Brettholz E, Pattersen GM, Delahunty T, Rotter JI. Increased intestinal permeability in patients with Crohn's disease and their relatives. Ann Intern Med 1986;105:883-5.

56. Shorter RG, Huizenga GA, Spencer RJ. A working hypothesis for the etiology and pathogenesis of nonspecific inflammatory bowel disease. Dig Dis Sci 1972;17:1024-31.

57. Walker AW, Isselbacher KJ. Uptake and transport of macromolecules by the intestine. Possible role in clinical disorders. Gastroenterology 1974;67:531-50.

58. Walker WA. Mechanisms of antigen handling by the gut. Clin Immunol Allergy 1982;2:15-34.

59. Bjarnason I, Macpherson A, Somasundaram S, Teahon K. Nonsteroidal anti-inflammatory drugs and inflammatory bowel disease. Can J Gastroenterol 1993;7:160-9.

60. Bjarnason I, Macpherson AJS, Somasundaram S, Teahon K. Non-steroidal anti-inflammatory drugs and Crohn's disease. In: Scholmeric J, Kruis W, Goebbell H, Hohenberger W, Gross V, eds. Inflammatory Bowel Diseases: Pathophysiology as Basis of Treatment. Falk Symposium no 67. Lancaster: Kluwer Academic Publishers, 1993:208-22.

61. Bjarnason I, Hayllar J, Macpherson AJ, Russell AS. Side effects of nonsteroidal anti-inflammatory drugs on the small and large intestine. Gastroenterology 1993;104:1832-47.

62. Auer IO, Habscheid W, Hiller S, Gerhards W, Eilles C. Nicht-steroidale antiphlogistika erhöhen die darmpermeabilität. Dtsch Med Wochenschr 1987;112:1032-7.

63. Bjarnason I, Williams P, Smethurst P, Peters TJ, Levi AJ. The effect of NSAIDs and prostaglandins on the permeability of the human small intestine. Gut 1986;27:1292-7.

64. Bjarnason I, Smethurst P, Clarke P, Menzies IS, Levi AJ, Peters TJ. Effect of prostaglandins on indomethacin induced increased intestinal permeability in man. Scand J Gastroenterol 1989;29(Suppl 164): 97-103.

65. Bjarnason I, Fehilly B, Smethurst P, Menzies IS, Levi AJ. The importance of local versus systemic effects of nonsteroidal anti-inflammatory drugs to increase intestinal permeability in man. Gut 1991;32:275-7.

66. Bjarnason I, Smethurst P, Macpherson A, et al. Glucose and citrate reduce the permeability changes caused by indomethacin in humans. Gastroenterology 1992;102:1546-50.

67. Bjarnason I, Zanelli G, Smith T, et al. Nonsteroidal antiinflammatory drug induced intestinal inflammation in humans. Gastroenterology 1987;93:480-9

68. Morris AJ, Wasson LA, Mackenzie JF. Small bowel enteroscopy in undiagnosed gastrointestinal blood loss. Gut 1992;33:887-9.

69. Rooney PJ, Jenkins RT, Smith KM, Coates G. 111-Indium-labelled polymorphonuclear scans in rheumatoid arthritis - an important clinical cause of positive results. Br J Rheumatol 1986;15:167-70.

70. Allison MC, Howatson AG, Torrance CJ, Lee FD, Russell RI.

Gastrointestinal damage associated with the use of nonsteroidal anti-inflammatory drugs. N Engl J Med 1992;327:749-54.

71. Smethurst P, Menzies IS, Levi AJ, Bjarnason I. Is alcohol directly toxic to the small bowel mucosa? Clin Sci 1988;75:50P-1P.

72. Parrilli G, Iaffaioli RV, Martorano M, et al. Effects of anthracycline therapy on intestinal absorption in patients with advanced breast cancer. Cancer Res 1989:49:3689-91.

73. Pledger JV, Pearson ADJ, Craft AW, Laker MF, Eastham EJ. Intestinal permeability during chemotherapy for childhood tumors. Eur J Pediatr 1988;147:123-7.

74. Pearson ADJ, Craft AW, Pledger JV, Eastham EJ, Laker MF, Pearson CS. Small bowel function in acute lymphoblastic leukemia. Arch Dis Child 1984;59:460-5.

75. Selby PJ, Lopes N, Mundy J, Crofts M, Millar JL, McElwain TJ. Cyclophosphomide priming reduces intestinal damage in man following high dose melphalan chemotherapy. Br J Cancer 1987;55:531-3.

76. Cooper BT, Ukabam SO, O’Brien IAD, Hara JPO, Corrall RJM.
Intestinal permeability in diabetic diarrhoea. Diabet Med 1987:4:49-52.

77. Ohri SK, Somasundaram S, Koak Y, et al. The effect of intestinal hypoperfusion during cardiopulmonary bypass surgery on saccharide permeation and intestinal permeability in man. Gastroenterology 1994;106:318-23.

78. Otamiri T, Sjodahl R, Tagesson C. An experimental model for studying reversible intestinal ischemia. Acta Chir Scand 1987;153:51-6.

79. Roumen RM, van der Vliet JA, Wevers RA, Goris RJ. Intestinal permeability is increased after major vascular surgery. J Vasc Surg 1993;17:734-7.

80. Coltart RS, Howard GC, Wraight EP, Bleehen NM. The effect of hyperthermia and radiation on small bowel permeability using ${ }^{51} \mathrm{Cr}$ EDTA and ${ }^{14} \mathrm{C}$ mannitol in man. Int $\mathrm{J}$ Hyperthermia 1988;4:467-77.

81. Ruppin H, Hotze A, During A, et al. Reversible funktionsstörungen des intestinaltraktes durch abdominelle strahlentherapy. Z Gastroenterol 1987;25:261-9.

82. Yeoh EK, Horowitz M, Russo A, Muecke T, Robb T, Chatterton BE. Gastrointestinal function in chronic radiation enteritis-effects of loperamide-N-oxide. Gut 1993;34:476-82.

83. Kardossis T, Joseph AEA, Gane JN, Bridges CE, Griffin GE. Fecal leucocytosis. Indium-111 labelled autologous polymorphonuclear leucocyte abdominal scanning, and quantitative fecal indium-111 excretion in acute gastroenteritis and enteropathogen carriage. Dig Dis Sci 1988;33:1383-90.

84. Leclercq-Foucart J, Forget P, Sodoyez-Gouffaux F, Zappitelli A. Intestinal permeability to ${ }^{51} \mathrm{CrEDTA}$ in children with cystic fibrosis. J Pediatr Gastroenterol Nutr 1986;5:284-7.

85. Leclercq-Foucart J, Forget $P, V$ an Cutsem JL. Lactulose-rhamnose intestinal permeability in children with cystic fibrosis. J Pediatr Gastroenterol Nutr 1987;6:66-70.

86. Dalzell AM, Freestone NS, Billington D, Heaf DP. Small intestinal permeability and orocaecal transit time in cystic fibrosis. Arch Dis Child 1990;65:585-8.

87. Escobar H, Perdomo M, Vasconez F, Camarero C, del Olmo MT, Suarez L. Intestinal permeability to ${ }^{51} \mathrm{Cr}$-EDTA and orocecal transit time in cystic fibrosis. J Pediatr Gastroenterol Nutr 1992;14:204-7.

88. Teahon K, Webster AD, Price AB, Bjarnason I. Studies of gastrointestinal 
structure and function in patients with primary hypogammaglobulinaemia. Gut 1994;35:1244-9.

89. Keating J, Bjarnason I, Somasundaram $\mathrm{S}$, et al. Intestinal absorptive capacity, intestinal permeability and jejunal histology in HIV infected patients and their relation to diarrhoea. Gut. (In press)

90. Lim SG, Menzies IS, Lee CA, Johnson MA, Pounder RE. Intestinal permeability and function in patients infected with human immunodeficiency virus. Scand J Gastroenterol 1993;28:573-80.

91. Ukabam SO, Clamp JR, Cooper BT. Abnormal intestinal permeability to sugars in patients with Crohn's disease of the terminal ileum and colon. Digestion 1982;27:70-4.

92. Casellas F, Aguade S, Soriano B, Accarino A, Molero J, Guarner L. Intestinal permeability to ${ }^{99 \mathrm{~m}} \mathrm{Tc}$ diethylene-tetraaminopentaacetic acid in inflammatory bowel disease. Am J Gastroenterol 1986;81:767-70.

93. Resnick RH, Royal H, Marshall W, Barron R, Werth T. Intestinal permeability in gastrointestinal disorders. Dig Dis Sci 1990;35:205-11.

94. O'Morain C, Abelon AC, Chervli LR, Fleischner GM, Das KM. ${ }^{51}$ CrEDTA a useful test in the assessment of inflammatory bowel disease. J Lab Clin Med 1986;108:430-5.

95. Jenkins RT, Jones DB, Goodacre RL, et al. Reversibility of increased intestinal permeability to ${ }^{51} \mathrm{CrEDTA}$ in patients with gastrointestinal inflammatory bowel disease.

J Rheumatol 1987;82:1159-64.

96. Turck D, Ythier H, Maquet E, et al. Increased intestinal permeability to
${ }^{51}$ CrEDTA in children with Crohn's disease and coeliac disease. J Pediatr Gastroenterol Nutr 1987;6:535-7.

97. Pironi L, Miglioli M, Ruggeri E, et al. Relationship between intestinal permeability to $\left({ }^{51} \mathrm{Cr}\right)$ EDTA and inflammatory activity in asymptomatic patients with Crohn's disease. Dig Dis Sci 1990;35:582-8.

98. Sanderson IR, Boulton P, Menzies IS, Walker-Smith JA. Improvement of abnormal lactulose rhamnose permeability in active Crohn's disease of the small bowel by an elemental diet. Gut 1987;28:1073-6.

99. Teahon K, Smethurst P, Levi AJ, Bjarnason I. The effect of elemental diet on intestinal permeability and inflammation in Crohn's disease. Gastroenterology 1991;101:84-9.

100. Jenkins RT, Ramage JK, Jones DB, Collins SM, Goodacre RL, Hunt RH. Small bowel and colonic permeability to ${ }^{51} \mathrm{CrEDTA}$ in patients with active inflammatory bowel disease. Clin Invest Med 1988;11:151-5.

101. Pearson AD, Eastham EJ, Laker ME, Craft AW, Nelson R. Intestinal permeability in children with Crohn's disease and coeliac disease. BMJ 1982;285:20-1.

102. Teahon K, Smethurst P, Macpherson AJ, Levi AJ, Menzies IS, Bjarnason I. Intestinal permeability in Crohn's disease and its relation to disease activity and relapse following treatment with elemental diet. Eur J Gastroenterol Hepatol 1993;5:79-84.

103. Adenis A, Colombel JF, Lecouffe P, et al. Increased pulmonary and intestinal permeability in Crohn's disease. Gut 1992;33:678-82.
104. Howden CW, Robertson C, Duncan A, Morris AJ, Russell RI. Comparison of different measurements of intestinal permeability in inflammatory bowel disease. Am J Gastroenterol 1991;86:1445-9.

105. Wallaert B, Colombel JF, Adenis A, et al. Increased intestinal permeability in active pulmonary sarcoidosis. Am Rev Respir Dis 1992;145:1440-5.

106. Teahon K, Smethurst P, Levi AJ, Menzies IS, Bjarnason I. Intestinal permeability in patients with Crohn's disease and their first degree relatives. Gut 1992;33:320-3.

107. Ruttenberg D, Young GO, Wright JP, Isaacs S. PEG 400 excretion in patients with Crohn's disease, their first degree relatives, and healthy volunteers. Dig Dis Sci 1992;37:705-8.

108. Munkholm P, Langholz E, Hollander $\mathrm{D}$, et al. Intestinal permeability in patients with Crohn's disease and ulcerative colitis and their first degree relatives. Gut 1994;35:68-72.

109. Ainsworth M, Eriksen J, Rasmussen JW, Schaffalitzkydemuckadel OB. Intestinal permeability of ${ }^{51} \mathrm{Cr}$-labelled ethylenediaminetetra-acetic acid in patients with Crohn's disease and their first degree relatives. Scand J Gastroenterol 1989;24:993-8.

110. Katz KD, Hollander D, Vadheim CM, et al. Intestinal permeability in patients with Crohn's disease and their healthy relatives. Gastroenterology 1989;97:927-31.

111. May GR, Sutherland LR, Meddings JB. Is small intestinal permeability really increased in relatives of patients with Crohn's disease? Gastroenterology 1993;104:1627-32. 


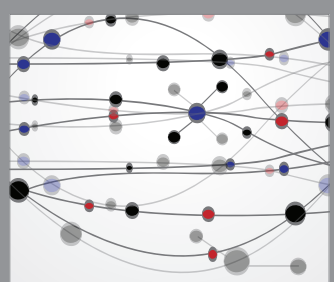

The Scientific World Journal
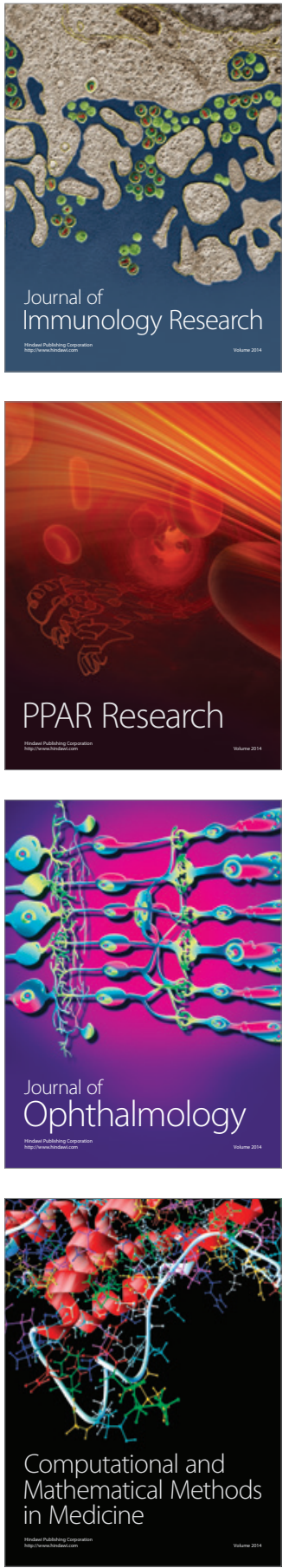

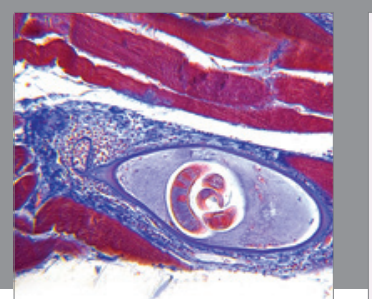

Gastroenterology Research and Practice

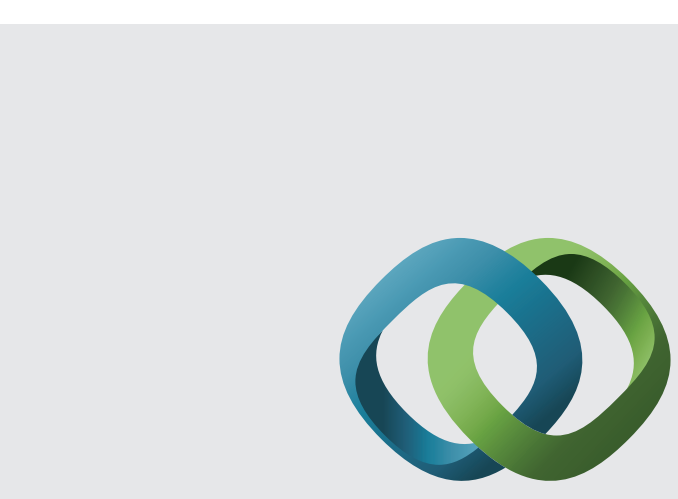

\section{Hindawi}

Submit your manuscripts at

http://www.hindawi.com
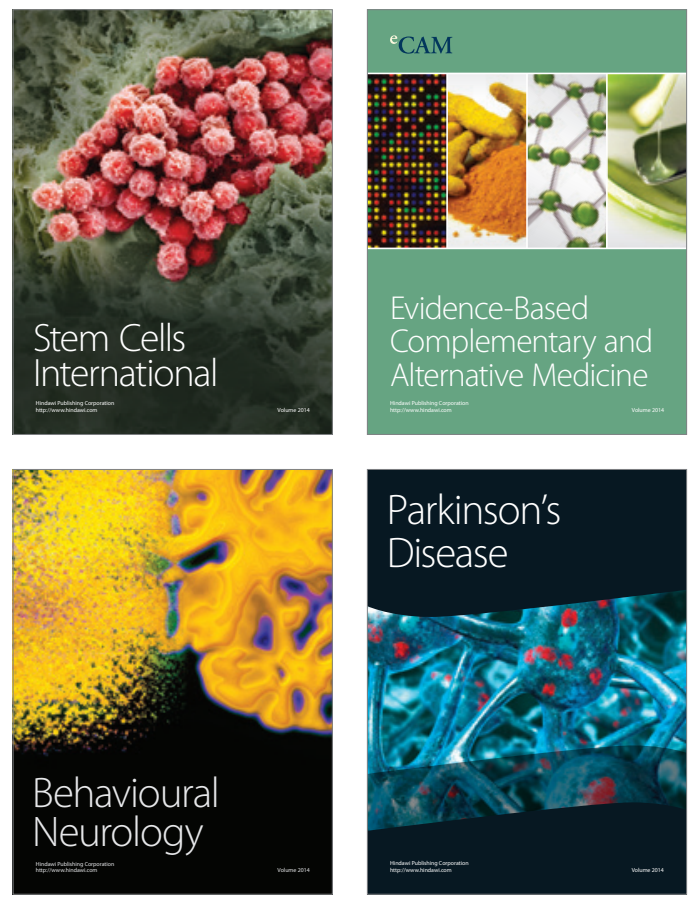
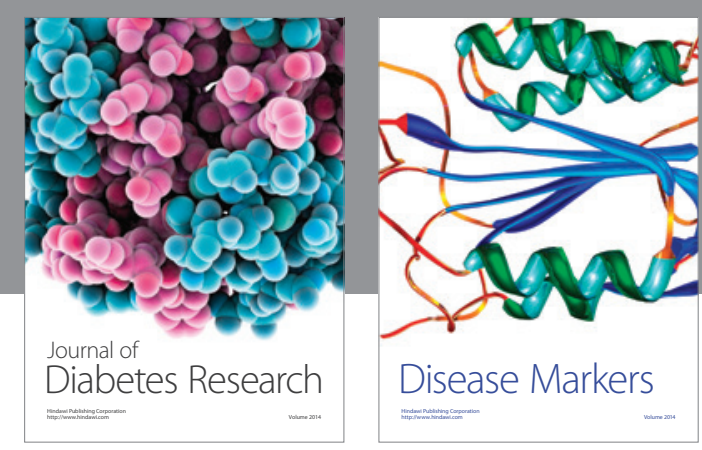

Disease Markers
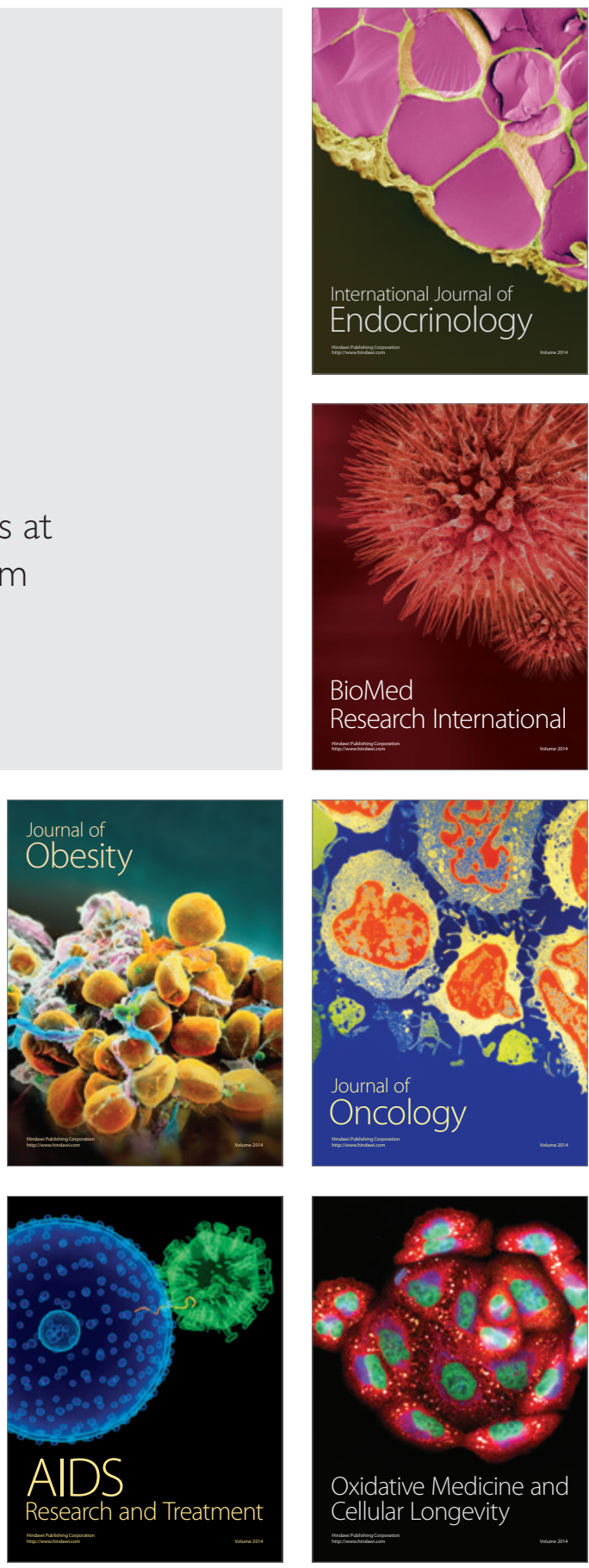